\title{
The Application of Flower Patterns on Cosmetics Package Design
}

\author{
Jie Tang \\ Shiyuan College \\ Guangxi Teachers Education University \\ Nanning, China
}

\author{
Haijun Tang \\ Shiyuan College \\ Guangxi Teachers Education University \\ Nanning, China
}

\begin{abstract}
With the continuous improvement of public aesthetic level, the function of product package design has been transferred from the practical function to the information transmission function. The package design of cosmetics with women as their main consumer groups is more special and unique, trying to use beautiful patterns and fashion elements to improve female consumers' impression on the cosmetics. From current fashion trend, the cosmetic package design likes to use flower patterns to bring consumers a fresh and natural feeling, and the specific emotional meanings of flowers also effectively enhance brands' sentimental value. This paper analyzed the expression forms, application methods, characteristics and principles of flower patterns in package design, and combined various cosmetic package design cases to show the specific application of flower patterns in cosmetic package design.
\end{abstract}

\section{Keywords—flower patterns; package design; application}

\section{INTRODUCTION}

In the past, due to the singleness of packaging containers and materials, decoration design and modeling design are not abundant. Even if there is a better design concept, it cannot be realized due to technical and material constraints. With the development of the times and the progress of technology, more and more new elements have been applied to the cosmetic package design. Cosmetic package design need to show personal needs of different consumers, express the aesthetic tastes of different people groups, so that the sale of cosmetics can be successfully achieved.

Flower patterns, with a rich variety and a unique beauty of artistic conception, are the comprehensive embodiment of designers' thinking and artistic accomplishments, and transmit the beauty to more people by the application of flower patterns, triggering emotional resonance. The use of flower patterns in cosmetic package design is a more common form of creation, which not only enhances the cultural connotation and commercial value of commodity packaging, but also shows a better visual image.

\section{THE EXPRESSION FORMS OF FLOWER PATTERNS IN COSMETIC PACKAGES}

The flower patterns in cosmetic packaging are of bright colors, with elegant package design. Compared to other product packaging, it is more eye-catching, and is conducive to attracting the attention of consumers and deepening the impression of consumers on products. Modern cosmetic package design, requiring the visual unity, not only needs to show the temperament characteristics of a single cosmetic, but also needs to maintain the overall sense of beauty and the visual impression in series of cosmetics. The design elements of cosmetic packaging are of a wide range, which can be reflected by shapes, colors and composition patterns, etc. The expression forms of flower patterns in cosmetic packaging can be divided into specific flower patterns, decorative flower patterns and geometric abstract patterns.

\section{A. Specific Flower Patterns}

Specific flower pattern is the most direct form of expression, and there are different expression techniques, such as photography and realistic painting, etc. The technique of Photography can directly convey information to consumers through exquisite images, and deepen consumers' recognition of brands, to make purchasing desire. As Innisfree series of cosmetics were shown in "Fig. 1", the product package design took use of the realization method of photography, which is the direct use of processed photographic images directly convey products information to consumers.

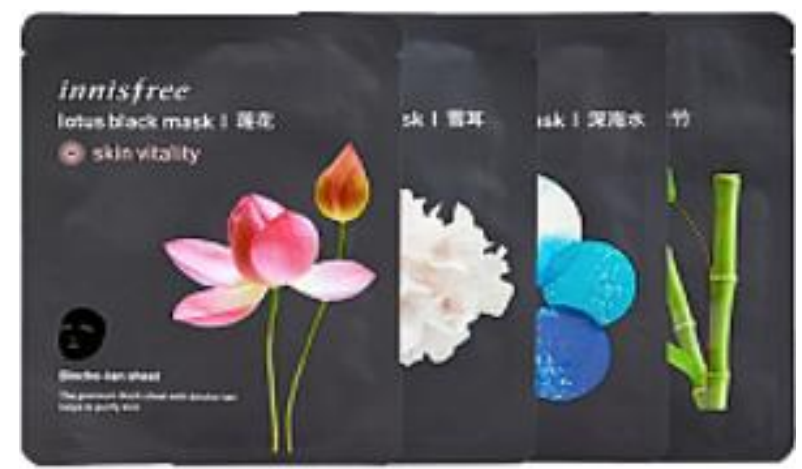

Fig. 1. Innisfree Series of Cosmetics

Realistic painting is more flexible than the photography technique, which is not only the realistic representation of products but also the further beautifying and processing of products. Painting techniques can produce different visual effects by different design techniques, so as to fully convey the feelings contained in the products. As the series of cosmetic package design were shown in "Fig. 2", compared to the 
photographic expression techniques, the use of painting techniques to express emotions and to show personality to the consumers had a stronger visual impact on consumers.

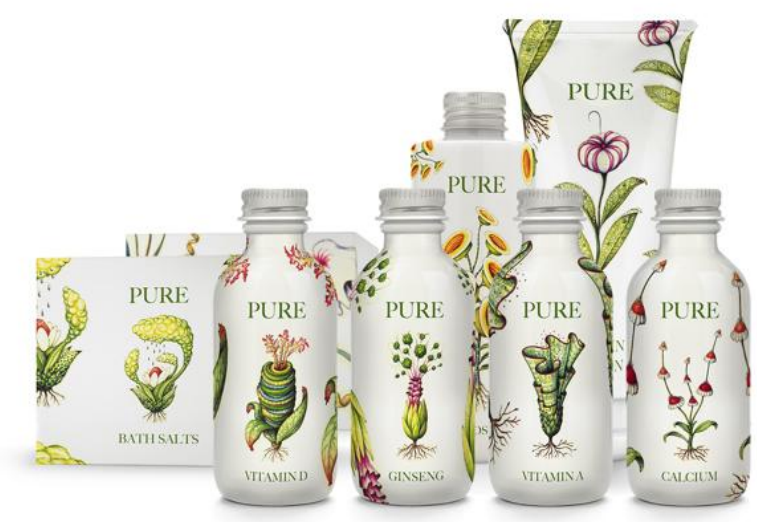

Fig. 2. Pure - healthy product packages with hand-drawn plants

\section{B. Decorative Flower Patterns}

Decorative flower pattern is decorating cosmetic packages with flower patterns, and then beautifying the product packaging, reflecting a taste and an artistic sense as well as expressing the designers' thoughts and creative ideas. Using decorative flower patterns in designs is to convey product information; the transmission of information is not the selftalking of designers, and they must put consumers as the objects of appeal. The re-design of flower patterns will transfer the information into creative ideas easy for consumers to understand. During this process, different meanings are given to flower patterns, and the information to be delivered are also infinitely extended in the works.

Because of different living environments, different plants have different meanings. Based on different characteristics of plants, people process and beautify those plants, and pass design emotions to consumers. Take Marc Jacobs Daisy series of fragrance "Fig. 3" for example. The fragrance bottle was designed by taking daisy flowers as prototype, giving a fresh and elegant feeling. At the same time, the bottle body was also decorated and beautified. Its design of the golden flower cap is wildly favored by female consumers.

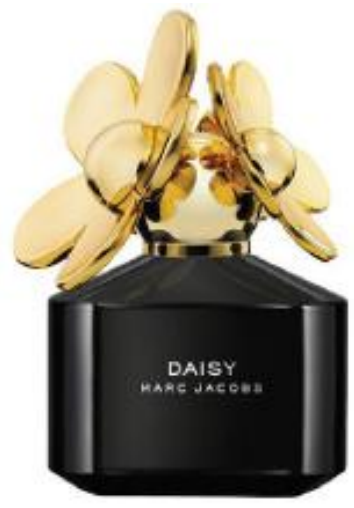

Fig. 3. Marc Jacobs Daisy Series of Fragrance

\section{Abstract Flower Patterns}

Abstract flower pattern is to process the flower pattern, through the way of extraction and generalization, into geometric patterns like dots, lines and surfaces. The main purpose of abstract patterns is to depict the temperament and image characteristics of products, which is a technique used to describe things that are difficult to express with specific patterns. As it was shown in "Fig. 4", the cosmetic package design combined dots, lines and surfaces to form a colorful pattern design.

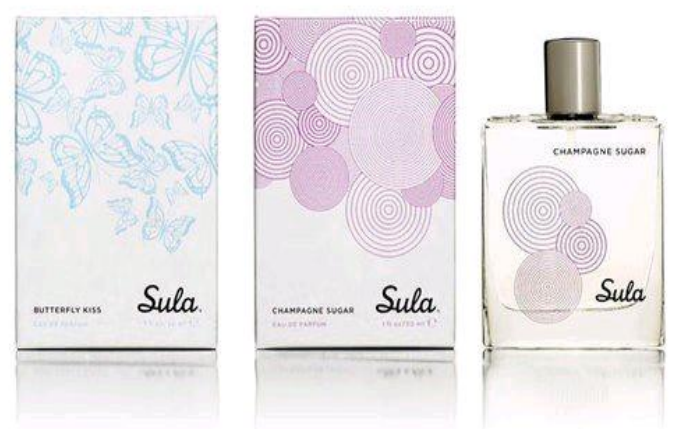

Fig. 4. Sula Skin Care Products

Abstract flower patterns play a decorative role in products, to attract the attention of consumers and prompt consumers' purchasing desire. Based on the aesthetic standard of most consumers, flower patterns are beautiful for people; geometric abstract patterns are redesigned, which brings a visual experience of fashion and simplicity and make products stand out among many other products with different packaging.

\section{THE APPLICATION METHODS OF FLOWER PATTERNS IN COSMETIC PACKAGE DESIGN}

\section{A. Direct Application}

Direct application, the most widely used form to use patterns, is to use patterns themselves to express the meaning of products. Flower by Kenzo is a typical example of direct application of flower patterns. Flower by Kenzo used a special tilted transparent bottle with a fire-red poppy flower as its design; its crystal and clear appearance shows the slim and strong, simple and elegant image of poppy flower. The time when it was launched, it became the NO.1 female perfume around the whole Europe. What's more special is that it is the first perfume with different appearances in different volumes: $30 \mathrm{ml}$ used flower buds going to burst, and $50 \mathrm{ml}$ used the joy of first blooming, and $100 \mathrm{ml}$ used blooming flowers, which symbolize different stages and processes of flower growth. Moreover, the curved lines of the bottle are just like the beauty of flowers swaying in the wind, charmingly. ${ }^{1}$ The " $\mathrm{D}$ ' Ete" perfume package design used leaves as the main design of the perfume bottle, which made consumers associate green leaves with the vitality and the beautiful feelings in the nature. The external packaging of the perfume is transparent, and the shape, veins and textures of the leaf are displayed on the packaging.

${ }^{1}$ http://www.yoka.com/dna/d/209/746.html 
What the entire package design passed to consumers is the vitality and the fresh and quiet condition of the nature, which is the message to consumers through the direct application of flower patterns.

\section{B. Indirect Application}

Not every designed flower patterns are real existences. Most designing works convey information in a very implied way, and indirectly show products by things related to the products. Indirect application consists of different expression forms, such as association and symbolization, etc.

Association can be concrete and also abstract. Through different design techniques to make consumers associate concrete flowers with happiness, golden leaves with autumn, abstract lines with the sea level, and lush green colors with grassland. The use of indirect application of association can convey to consumers meanings that cannot directly transmitted by direct images. A symbol is based on a certain kind of connection between things, with a specific image (a symbolic body), to express some kind of abstract concepts, thoughts and emotions. For example, lavenders are used to symbolize faith, romance; sunflowers are used to represent faith and glory; clovers are used to indicate luck and happiness, and so on.

"Fig. 5" is Estee Lauder Chantecaille the Coral pressed powder. The design inspiration of product packaging is from coral flowers, and the packaging took the blue ocean as the background color, which can easily make people associate with corals under the sea. The entire packaging brings consumers a feeling of presence at the scene, by which they feel they are watching the beautiful sceneries of the sea and feel the purity and naturality of the sea, with a sense of joy arising naturally.

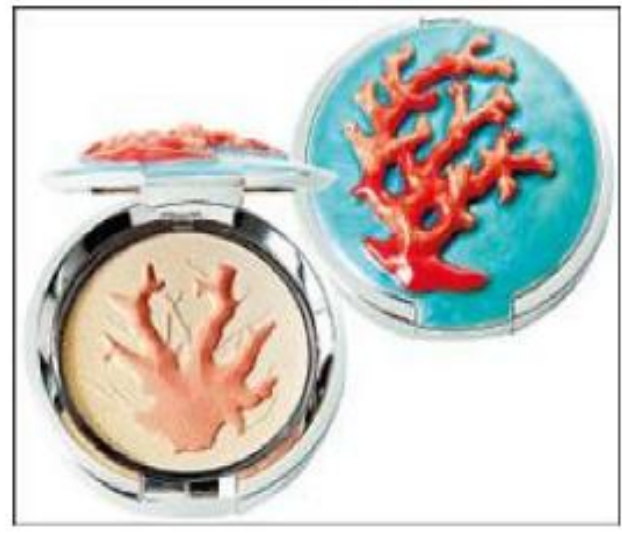

Fig. 5. Estee Lauder Chantecaille the Coral Pressed Powder

"Fig. 6" is the 16th anniversary limited gift box "Reflecting Beauty \& Meeting Love" launched by Herborist on Valentine's Day; the product package design used a fresh hand-painted style to depict an ancient love story, and is carefully designed by combining classic herbal elements and the symbol mark of love. The application of abundant colors and delicate lines of depiction made a series of classic love legends appear in people's sight with the symbol marks of love, which led consumers to comprehend the attitudes of love reflected by the stories: a pair of flying butterfly is a metaphor of Liang Shanbo and Zhu Yingtai's longing for pure and free love; a bridge of magpies surrounded by flowers and grasses is a metaphor of the warm and pleasant love of Dong Yong and the seventh fairy, etc. Through the reconstruction of those ancient classic love models, Herborist hopes to lead people to find the most real love in the numerous, complicated and blatant modern society. ${ }^{1}$

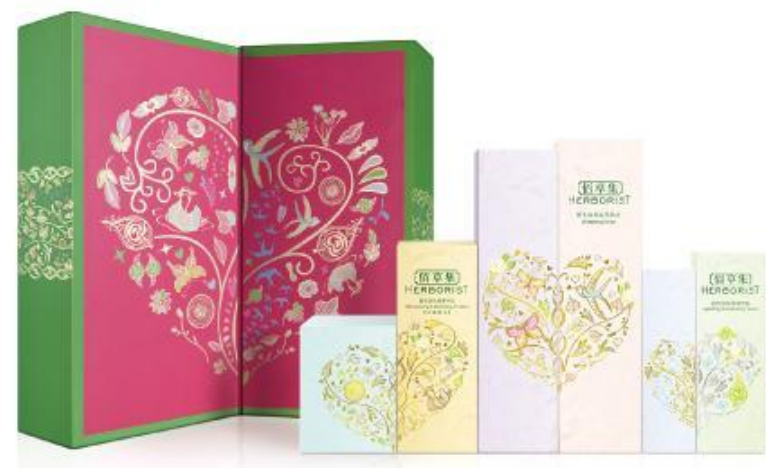

Fig. 6. Herborist Limited Gift box "Reflecting Beauty \& Meeting Love"

\section{Element Reconstruction}

Element reconstruction, based on a certain purpose and the inherent relevancy between things, makes meaningful integration and configuration of different existing elements, to develop new ideas, new images or new functions of patterns. The reconstruction of flower patterns is to break up the organizational structure of flower patterns, and select the most characteristic symbols in flower patterns, and reconstruct them into new symbols in accordance with contemporary consumers' aesthetics. The purpose of element reconstruction is to blend flower patterns into the concept of contemporary package design, and then reflects the temperament and spirit of Chinese traditional culture. In "Fig. 7", new pattern symbols were formed by the innovation of basic symbols of flower patterns. Based on initial flower patterns, pattern forms were selected in an abstract way; according to the characteristics of products and the designer's creativity, new flower patterns were designed and formed by the reconstruction of elements to meet modern aesthetic consciousness, which also retained the new patterns of the flower pattern forms.

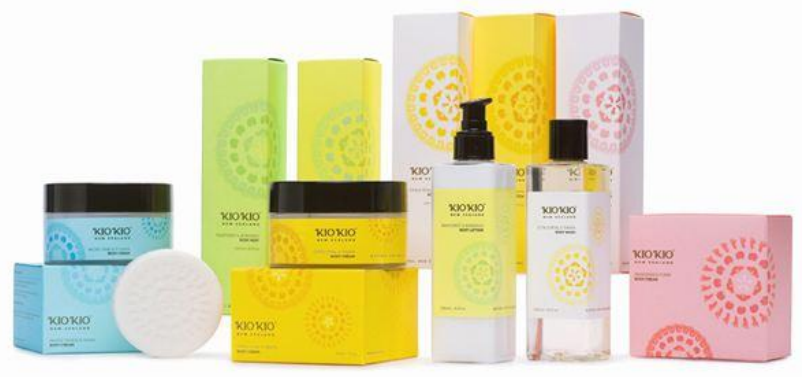

Fig. 7. KIO KIO Skin Care Products

${ }^{1}$ http://www.vogue.com.cn/beauty/new-in-

store/news 16339d832928e917.html, from VOGUE. 


\section{THE APPLICATION PRINCIPLES OF FLOWER PATTERNS IN COSMETIC PACKAGE DESIGN}

\section{A. Flower Patterns Must be Related to a Brand Itself.}

Patterns are produced through the communication of human beings. The original flower patterns have functions, such as totem logo, cultural exchange or anti-skid decoration. During the period of Dynasty Shang and Dynasty Zhou, there were only a small amount of flower and plant dermatoglyphic patterns, such as four-petal flower patterns and transformative leaf patterns, lotus patterns and other flower patterns. During the Spring and Autumn period and the Warring States period, the overall style of flower patterns showed a regular, fine, sumptuous, lively, smart feeling, and it was a combination of practice and aesthetics, as well as connotations and forms. During Qin and Han Dynasties, the flower patterns possessed unadorned and splendid feelings, as well as Romantic and elegant temperament. In Tang Dynasty, the flower patterns were more sophisticated and complicated. In Song Dynasty, flower patterns were light-colored and implied. In Ming Dynasty, the flower patterns showed maturely delicate. In Qing Dynasty, the flower patterns were full of the splendor of jewels, complicated and sophisticated, describing to us that society's aesthetics and fashion. All these are explaining that patterns have the function of expressing meanings. These patterns are not only the representatives of aesthetics in different ages, but also the symbols of the progresses made in each age. The purpose of package design is to make products conform to the aesthetic standard of today's society, and to attract consumers by their beautiful external forms. However, not all cosmetic brands can use flower-pattern package design. If a brand's culture, history, image, product personality and main ingredients have no connection with flowers, it is not suitable for the brand to use flower patterns in its package design; or it will give a very stiff and far-fetched feeling, which cannot achieve the beautifying effect of packaging, but also gives consumers wrong information to misunderstanding the brand. Only when a brand itself is inherently related to flowers, can the use of flower-pattern packaging show more prominent brand advantages.

\section{B. Flower Patterns Must Conform to the Connotation of Products.}

Different flower patterns contain different cultural connotations, and different products also have different corresponding product personalities and images. The function of packaging is to help consumers understand product information quickly and effectively, and to assist product promotion and promotion at the same time. Therefore, package design needs to ensure that the meaning of flower patterns is consistent with the information conveyed by products. If flower patterns own meanings and product connotations have divergences, it will lead to the reduction of consumers' favorability and credibility, and will also affect consumers' final purchase decisions. The flower patterns used in package design, after a high degree of condensation, materialize the beautiful wishes and ideals of designers, and blend them into product connotations to express product personality, giving people the enjoyment of beauty. This kind of compliance is easier to stimulate people's psychological reactions and resonances.

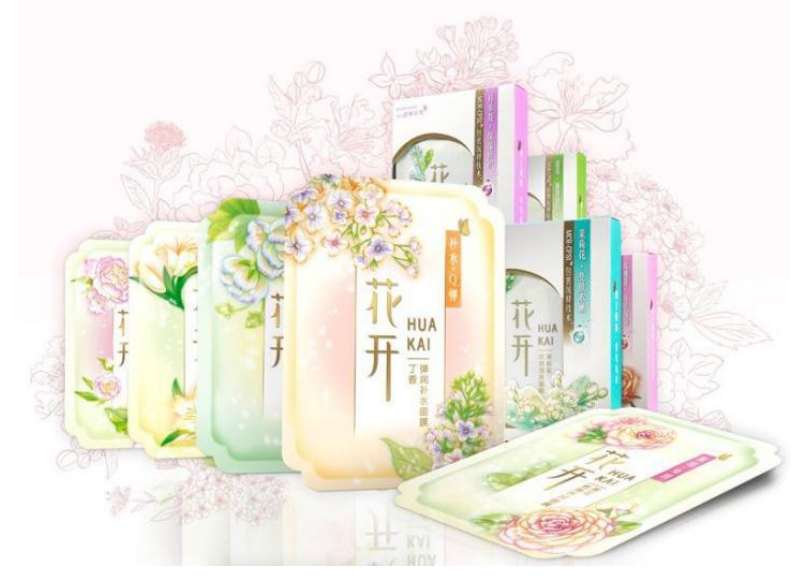

Fig. 8. Inoherb "Hukai” Face Masks

Inoherb "Fig. 8" took full account of the difference of each cosmetic product ingredients in its package design. After the determination of its product information, the corresponding flower patterns were selected to do its package design, which not only helps effectively distinguish the ingredients of different products from their effects, but also allows consumers to quickly and accurately choose the products they want.

\section{THE APPLICATION CHARACTERISTICS OF FlOWER PATTERNS IN COSMETIC PACKAGE DESIGN}

\section{A. Two kinds of Pattern Modeling - Specific and Abstract}

Specific patterns are mainly manifested by photography and realistic paintings. Abstract patterns are processed beautified on the basis of specific patterns, and they can avoid the limitations of specific patterns. When flower patterns use abstract patterns, attention should be paid on the creation and design of contours, charm, temperament and other aspects. Specific patterns and abstract patterns are two comparatively common expression methods of package design, both of which transmit information to consumers more directly.

In "Fig. 9", the Jurlique packaging on the left used specific patterns to design, so consumers can directly perceive the product's herbal recovery effect through flower patterns in the packaging. The Herborist packaging design on the right used abstract patterns. It was carefully created from the selection of flower patterns and styles to the stage of finalization. The ultimate semi-circular modeling effect imperceptibly tells consumers that their products are rich of herbal ingredients. 


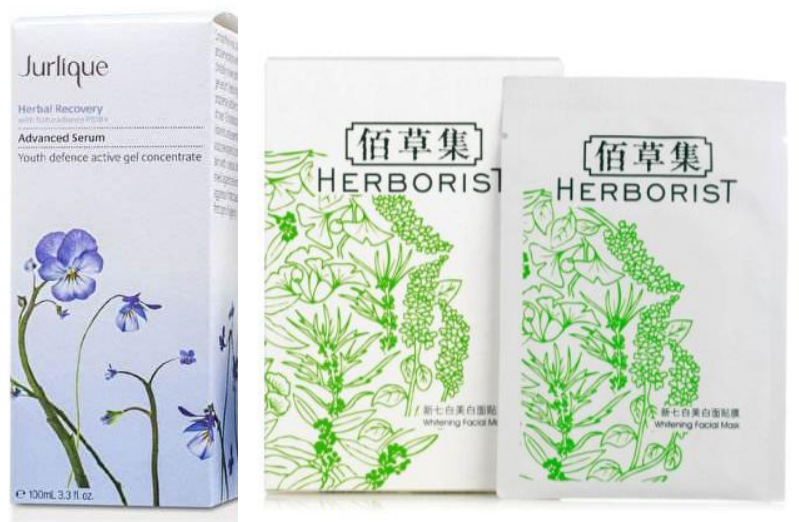

Fig. 9. The left one is Jurlique Skin Care product; the right ones are Herborist Skin Care products.

\section{B. Different Pattern Choices: as theme or as Sub-Theme}

According to the conditions of products and brands, the application of flower patterns in the package design can be divided into two type, theme and sub-theme. Flower patterns directly applied to the brand's image recognition belong to the type of theme; flower patterns directly used on specific product package design belong to the type of subtheme. For example, the famous French cosmetic brand "Lancome" is a successful brand that has successfully used flower patterns flowers as themes and sub-themes. Lancome's logo used a rose flower pattern. Roses symbolize love, beauty and elegance, which match women's emotional needs. The design of the logo gives people a simple and elegant sense. On the aspect of product segmentation, flower patterns were used as sub-theme, and different flower-pattern designs were used in different products. For instance, the packaging of its perfume series used rose patterns, and its skin care products used lotus patterns in the packaging, to express different product images through the use of different flower patterns which is conducive to the promotion of its brand cognition. Sub-theme is the interpretation of theme, and also the echo of theme. Two of them complement each other very well.

The outer packaging box of One Leaf Plant Enzyme Series used the expression method of taking flower pattern as subtheme. The look of mask bags used hollow design, and a "leaf" shape will immediately make people associate with the design of One Leaf. Moreover, real plant pictures were used in the design, whose appearance can let people know which products of which series without more words to describe. On the aspect of visual experience for consumers, bright colors and images of real fruits and vegetables give people a very "fresh" impression, which will stimulate consumers' purchasing desire.

\section{Pattern Colors - Both Natural Colors and Decorative Colors}

In the nature, various flowers, compete with each other for beauty, in all colors. Different colors bring different personality characteristics of flowers, such as the fresh and romantic personality of babysbreath, the pure and noble personality of lily, the clean and upright personality of lotus and so on. The natural colors used in flower-pattern package design are easier to narrow the distance between consumers and products. However, with the development of the society, flower patterns not just concentrate on natural colors. More and more designers try to add decorative colors in package design to make flower patterns more of the sense of the contemporary time. Simple, stylish and highly recognizable flower patterns are increasingly favored by consumers.

From the package design of Innisfree in "Fig. 10", the colors used in the packaging are mostly designed according to the natural colors of flowers, but decorative colors were added in by designers to improve the contrast of flowers and leaves. It is eye-appealing but not very abrupt, and also well highlights the brand image of Innisfree, and brings consumers a sense of embracing the nature, which conveys the beauty of health to every consumer.

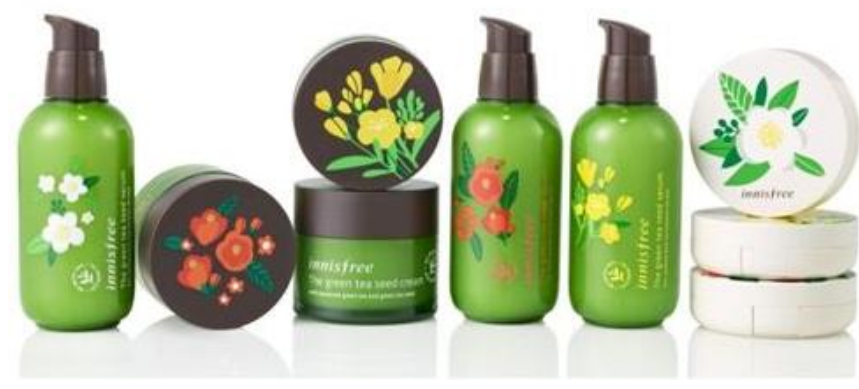

Fig. 10. Innisfree Skin Care products

\section{CONCLUSION}

One of the purposes of using flower patterns in cosmetic package design is to beautify product packaging; through the flower patterns, the personality characteristics of products can be conveyed through the flower patterns, to enhance the sentimental value of products, which is another purpose. In cosmetic package design, the intuition and vitality shown by the design of flower patterns effectively convey the product information to consumers, and let the products stand out from many other products and make consumers an unexpected impression.

Flower patterns not only add beautiful elements into the development of cosmetic package design, but also bring endless inspirations for modern designers. With the continuous application of new materials and new techniques, flower patterns will have wider and wider application range, and expression methods will be performed more incisively and vividly, which is worth our continuous exploration and research.

\section{REFERENCES}

[1] He Ji and Dong Xinhua.2015. "Brief Discussion on the Basic Principles insisted by Brand Package Design" [J]. Journal of Tongji University.

[2] Zhang Jing and Deng Hailian.2010. "Package Design Modeling" [M]. Guangxi Arts Publishing House. 
[3] Lai Fuxi and Hu Zhijun.2014. "The Problem Analysis on the Package and Design of Modern Enterprise Product Brands" [J]. Journal of Beijing Aesthetics College.

[4] Fu Liming.2013. "The Study on Design Aesthetic Laws" [M]. China Fine Arts Publishing House.

[5] Xia Zhiliang and Ye Zhenhe.2012. "Package Design" [M]. China Light Industry Press. 